\title{
Prevalence of Double Nutrition Burden Among Adolescent Girls of Assam, Northeast India
}

\author{
Sharma J ${ }^{1}$, Mondal $\mathbf{N}^{2}$
}

\begin{abstract}
Introduction: Prevalence of the malnutrition is a very common phenomenon in the developing countries leads to high mortality, morbidity and long-lasting physiologic effects. The present study was conducted among adolescent populations residing in rural regions with an aim to determine the prevalence of double nutritional burden (e.g., thinness and overweight) in Karbi-Anglong district of Assam, Northeast India. Materials and Methods: The present cross-sectional study was conducted among 1228 heterogeneous groups of adolescent girls aged 1016 years residing in rural areas of Diphu, Karbi-Anglong, Assam is using simple random sampling method. The anthropometric measurement of height and weight were recorded using the standard procedure. The Body mass index (BMI=weight/height ${ }^{2}$, $\mathrm{kg} / \mathrm{m}^{2}$ ) was calculated. Recently proposed, the BMI based agesex specific international references and cut-offs of Cole et al. was used to assess the prevalence of thinness and overweight. Results: The overall prevalence of overweight and thinness was found to be $8.13 \%$ and $19.14 \%$ respectively. The age specific prevalence of overweight and thinness was found to be higher among 11 years (12.00\%) and 16 years (31.13\%) respectively. Conclusion: The present study shows the magnitude of thinness is a still greater nutritional problem than overweight in rural adolescent girls in India. The results of the present study will be useful for the policy makers in their endeavour to formulate various developmental strategies and health care programmes of the population concern to combat the double burden of nutrition.
\end{abstract}

Key words: Thinness, Overweight, BMI, Adolescent, NortheastIndia, Anthropometry

\section{Introduction}

$\mathrm{P}$ revalence of the malnutrition is a very common phenomenon in the developing countries leads to high mortality, morbidity and long-lasting physiological effects ${ }^{1}$. The South Asian countries have particularly shown drastic changes in the nutritional status in the past few decades, primarily due to the changes in the socioeconomic status, dietary and lifestyle habits. Recent trends of population transition in the economic, demographic, epidemiological, nutritional and sociological fronts have decreased undernutrition
'Jyotismita Sharma, MA, Research Scholar, ${ }^{2} \mathrm{Dr}$. Nitish Mondal M.Sc, Ph.D, Assistant Professor. Both from the Department of Anthropology, Assam University: Diphu Campus, Karbi Anglong 782 462, Assam, India.

\section{Address for correspondence:}

Dr. Nitish Mondal, Assistant Professor,

Department of Anthropology,

Assam University: Diphu Campus,

Karbi Anglong 782 462, Assam, India,

E-mail: nitishanth@gmail.com

Tel: +91-9613712613

\section{How to cite}

Sharma J, Mondal N. Prevalence of Double Nutrition Burden Among Adolescent Girls of Assam, Northeast India. J Nepal Paediatr Soc 2014:34(2):132-137.

doi: http://dx.doi.org/10.3126/jnps.v34i2.10447

This work is licensed under a Creative Commons Attribution 3.0 License.

(c) (i)

with acceleration in overweight and obesity, ${ }^{2-5}$ but the highest proportion (463 million) of undernourished people is living in Asia $^{3}$. Current trend shows the prevalence of overweight and obesity are epidemic is an ever-growing concern in developed countries and also frequent in urban areas in developing countries including India ${ }^{3,4}$. Therefore, the prevalence of double burden of nutrition is simultaneously more prevalent in the socio-economically deprived segments and overweightobesity among more affluent were well recognized, but recent changes tend to 
result in the opposite manifestation causes double nutritional burden ${ }^{2-5}$. It is therefore important to assess overweight-obesity and be able to classify its severity in the population. The non-invasive and inexpensive, practical technique of anthropometry has become a widely used in assessing nutritional status, especially in clinical and epidemiological studies ${ }^{2,6}$. The Body Mass Index (BMI) classification is the most widely used surrogate anthropometric measures for assessing both undernutrition (e.g., thinness) and overweightobesity $4,6,7,8,9,10,11$.

Due to its immense population size, socioeconomic disparities, illiteracy and inadequate access to the healthcare facilities, the assessment of nutritional status have the potential to play a significant role in implementing development strategies in Indian populations ${ }^{3,5,12}$. It is evident that the national policy response to reduce the magnitude of malnutrition in India is still restricted to the undernutrition ${ }^{3,5}$. Several researchers have primarily focused on the magnitude of undernutrition in different Indian children and adolescents ${ }^{9,10,11,12,13,14,15,16,17,18}$. Therefore, assessment of nutritional status is considered to be the prime indicator of the health situation which interacts with the demographic and socioeconomic variables in important ways ${ }^{10,12,13,16,17}$. Currently, it is estimated that adolescents contributes to 1.20 billion of the total world population and belonging to the largest population of adolescent cohort of 243 million $(20.00 \%)$ in India ${ }^{18}$. Researchers have already reported that the prevalence of thinness (low BMI-for-age) is the major nutritional problem among adolescents in India $9,10,13,14,15,18,19$. Recent studies have also reported a significant proportion of the population residing in urban areas are being affected by overweight and obesity 3,4,20,21,22,23 as a manifestation these populations experienced double nutritional burden. Furthermore, the use of $\mathrm{BMI}$ in relation to age was recommended as the best surrogate anthropometric measure of thinness and overweight during adolescents ${ }^{6,7,8}$. Given above, the present study was conducted among adolescent girls population residing in rural areas with an aim to determine the prevalence of double nutritional burden (e.g., thinness and overweight) of Assam, Northeast India.

\section{Materials and Methods}

The present cross-sectional study was conducted among the adolescent girls in Diphu, Karbi-Anglong, Assam, Northeast India. The district Karbi-Anglong $\left(25^{\circ} 33^{\prime} \mathrm{N}\right.$ to $26^{\circ} 35^{\prime} \mathrm{N}$ latitude and $92^{\circ} 10^{\prime} \mathrm{E}$ to $93^{\circ} 50^{\prime} \mathrm{E}$ longitude) is the largest district among the
27 districts of Assam and covers an area of 10,434 $\mathrm{km}^{2}$. According the National Census, 2011 the district had a population of $9,56,280$ individuals $(4,93,482$ male; 4,71,798 female) with an average literacy rate of $59.52 \%$ (56.82\% male; $43.18 \%$ female). A total of 6 schools in the adjacent areas of Diphu were covered and total student strength of the schools was identical. The community area has a habitat of the major tribal population, predominantly Karbi and other ethnic group includes Dimasa, Bodo, Tiwas, Khasi and Rengma Naga tribal ethnic groups. A total of 1306 subjects belonging to heterogeneous ethnic groups were identified and adolescents belonging to the age group 10-16 years were approached. A total of 1228 adolescent girls aged $10-16$ years were included using simple random sampling method. The age of the subjects was recorded from the school records and was subsequently verified from birth certificates. The anthropometric data was collected during the period of January-December, 2013. The necessary study approvals and clearance were obtained from the school authorities and local community leaders prior to the commencement of study. All the subjects were free from any physical deformities, systematic diseases, nutritional deficiencies and previous surgical episodes. The investigation was conducted in accordance with the ethical guidelines of the human experiments as laid down in the Helsinki Declaration ${ }^{24}$.

\section{Collection of the anthropometric data}

The anthropometric measurement of height and weight of the subject was recorded using the standard procedure ${ }^{25}$. Height of the subject was recorded to the nearest $0.10 \mathrm{~cm}$ with the help of an anthropometer rod (GPM type, Galaxy Informatics, New Delhi) with the head held in the Frankfort horizontal plane. The weight of the subjects, wearing minimum clothing and with bare feet was taken using a portable weighing scale (Libra ${ }^{\circledR}$, Edryl-India, Tiswadi, Goa) to the nearest $100 \mathrm{gm}$. The anthropometric instruments were also checked in regular interval to reduce the systematic errors during measurement collections. The BMI was calculated by using the standard equation: $\mathrm{BMl}=$ weight $/$ height $^{2}, \mathrm{~kg} /$ $\mathrm{m}^{2}$ ). The difference in anthropometric measurements was calculated for testing the co-efficient of reliability $\left[R=\left\{1-(T E M)^{2} / S D^{2}\right\}\right.$, the $S D=$ standard deviation of all measurements] using the technical error measurement $\left\{T E M=V \quad\left(\Sigma D^{2} / 2 N\right), \quad D=\right.$ difference between the measurements, $\mathrm{N}=$ number of individuals measured $\}$ following the method of Ulijaszek and $\mathrm{Kerr}^{26}$. A total of 50 subjects were identified using simple random sampling method for calculation of TEM analysis. Very high values of $R(>0.98)$ were obtained for height and weight using TEM analysis and values were found within 
the cut-off value $(R=0.95)^{26}$. Hence, the anthropometric measurements were obtained in this study are free from observer bias, reproducible. The TEM values were not considered for further statistical consideration, and all the measurements were subsequently recorded by the author JS.

\section{Assessment of nutritional status}

The prevalence of thinness ${ }^{7}$ and overweight ${ }^{8}$ were assessed using recently proposed age-sex specific international reference and cut-offs. The prevalence of thinness was proposed similar to the cut-offs of adult chronic energy deficiency (CEC) (BMI<18.50 kg/ $\left.\mathrm{m}^{2}\right)$ and overweight $\left(\mathrm{BMI} \geq 25.00 \mathrm{~kg} / \mathrm{m}^{2}\right)^{6,7,8}$. These references and cut-off points are already utilized to assess and document such prevalence among Indian adolescents $s^{9,13,14,22}$.

\section{Statistical analysis}

Statistical analyses were done using the Statistical Package for Social Science (SPSS, version 17.0). Normality was tested using the Shapiro-Wilk test for each of the anthropometric variable age groups-wise, and $p$-values observed were statistically not significant in most of the categories $(p>0.05)$. The data were analysed in terms of descriptive statistics of mean and standard deviation (SD). One way analysis of variance (ANOVA) was done to assess the age specific mean difference in anthropometric variables. The chi-square analysis was utilized to assess differences in nutritional indices between different Indian ethnic groups. The p-values of $<0.05$ were considered to be statistically significant.

\section{Results}

Age specific subject distribution, descriptive statistics (mean $\pm S D$ ) of height, weight and BMI among adolescent girls is depicted in Table 1. The overall mean \pm SD of height, weight and BMI were $147.76 \pm 7.69 \mathrm{~cm}$, $40.51 \pm 8.14 \mathrm{~kg}$ and $18.40 \pm 2.64 \mathrm{~kg} / \mathrm{m}^{2}$ respectively. The age specific mean height and weight was increased with age with an exception, observed in 16 years (in height). However, age-specific trend was found to be absent in mean BMI but there was a positive increase when approached to higher ages with an exception observed in 14 years and 16 years. The age specific mean BMI was ranged from $16.36 \pm 1.94 \mathrm{~kg} /$ $\mathrm{m}^{2}$ (in 10 years) to $19.56 \pm 2.57 \mathrm{~kg} / \mathrm{m}^{2}$ (in 16 years). Using ANOVA, the age specific mean differences were observed to statistically significant $(p<0.01)$ in weight $(F$-value $=125.23 ;$ d.f. $6 ; 1227)$, height $(F-$ value $=119.23$; d.f. $6 ; 1227$ ) and BMI (F-value= 60.98; d.f. 6;1227). The overall prevalence of overweight and thinness using BMI classification proposed by Cole et al. ${ }^{7,8}$ was found to be $8.31 \%$ and $19.14 \%$, respectively (Figure 1 ). The age specific prevalence of thinness and overweight was found to be higher among 16 years (31.13\%) and 11 years (12.00\%) respectively. The age-specific lower prevalence of thinness and overweight was observed among 15 year (9.03\%) and 14 years (3.23\%). However, age-specific trend in the prevalence of thinness and overweight was found to be absent among adolescent girls, but the prevalence of thinness was observed to be greater ( $>20.00 \%)$ in early and higher age groups (e.g., 10-12 and 16 years) (Figure 1).

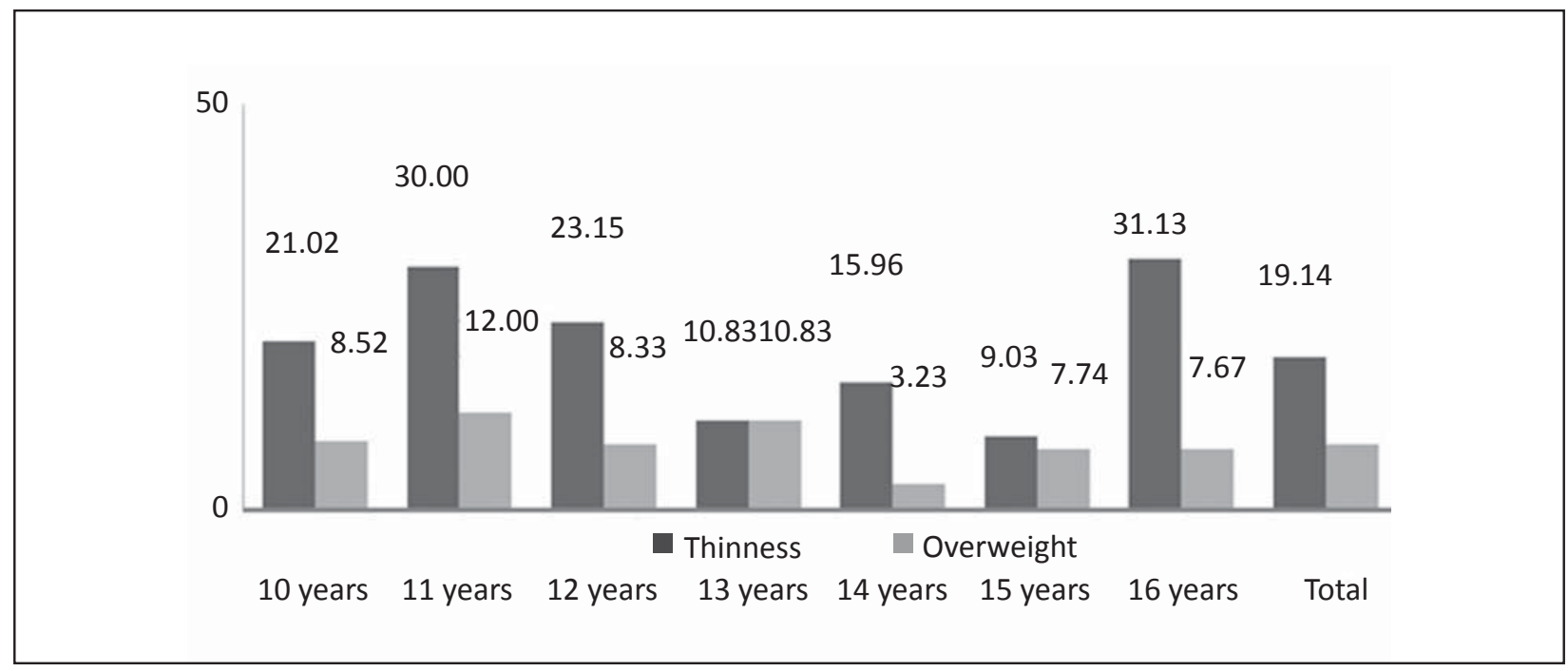

Fig 1: Age specific and overall prevalence (in percentages) of thinness and overweight amongst adolescent girls of Karbi-Anglong, Assam 
Table 1: Age specific subject distribution, descriptive statistics (mean \pm SD) of weight, height and BMI among adolescent girls of Karbi-Anglong Assam

\begin{tabular}{|c|c|c|c|c|}
\hline Age & Subjects & Weight $(\mathbf{k g})$ & Height $(\mathbf{c m})$ & $\mathbf{B M I}\left(\mathbf{k g} / \mathbf{m}^{\mathbf{2}}\right)$ \\
\hline 10 years & 176 & $31.51 \pm 5.86$ & $138.27 \pm 7.36$ & $16.36 \pm 1.94$ \\
\hline 11 years & 150 & $35.61 \pm 7.35$ & $144.34 \pm 7.53$ & $16.97 \pm 2.57$ \\
\hline 12 years & 216 & $38.55 \pm 7.30$ & $146.84 \pm 6.32$ & $17.78 \pm 2.52$ \\
\hline 13 years & 240 & $43.13 \pm 6.46$ & $149.80 \pm 5.08$ & $19.19 \pm 2.44$ \\
\hline 14 years & 188 & $44.11 \pm 5.56$ & $151.87 \pm 5.56$ & $19.11 \pm 2.07$ \\
\hline 15 years & 155 & $46.77 \pm 5.69$ & $152.30 \pm 5.16$ & $20.14 \pm 2.09$ \\
\hline 16 years & 103 & $45.03 \pm 6.28$ & $151.76 \pm 5.55$ & $19.56 \pm 2.57$ \\
\hline Total & $\mathbf{1 2 2 8}$ & $\mathbf{4 0 . 5 1 \pm 8 . 1 4}$ & $\mathbf{1 4 7 . 7 6 \pm 7 . 6 9}$ & $\mathbf{1 8 . 4 0 \pm 2 . 6 4}$ \\
\hline
\end{tabular}

\section{Discussion}

The prevalence of malnutrition is continuing to be the major nutritional problem, especially in rural population of India due to widespread poverty, socioeconomic disparities and the scarcity of basic healthcare amenities problem mostly reflecting among vulnerable segments ${ }^{9-15}$. The prevalence of the thinness due to chronologically poor conditions are very common in much of the developing countries like India ${ }^{9,18}$. Therefore, the present study emphasized the importance of identifying the magnitude of undernutrition (e.g., thinness) and overweight to provide an insight into the public health condition and establish the need of appropriate intervention strategies in a heterogeneous rural adolescent population of Northeast India. Several studies have already advocated that the prevalence of undernutrition is better assessed as thinness rather than wasting (low weight-for-height) $6,7,14,15$. The present study assesses the prevalence of thinness and overweight using newly proposed reference ${ }^{7,8}$. These references were suggested to encourage direct comparison of global trends in thinness and overweight prevalence and to provide a classification for the public health purpose.

Several studies have reported that the problem of thinness is persistent transversely among different Indian populations with consistent proportions, especially among Indian children and adolescents ${ }^{9}$, $10,12,13,14,17,19$. When the prevalence of the thinness of the present study was compared with Indian population, it has been observed that tribal Sonowal Kachari ${ }^{15}$ (23.92\%) and Indian adolescent girls ${ }^{16}$ (41.30\%) were significantly $(p<0.05)$ affected in Assam. Venkaiah et al. ${ }^{17}$ also reported that the prevalence of thinness to be significantly higher among rural adolescent girls (39.50\%) $(p<0.05)$. Recently, lower prevalence of thinness was reported among tribal Karbi adolescent population of Assam (14.90\%) ${ }^{19}(p>0.05)$. A significantly greater prevalence of thinness among adolescent girls (30.61\%) has also been reported from North India ${ }^{27}$ (30.61\%) and Darjeeling, West Bengal ${ }^{14}$ (46.89\%) $(p<0.05)$. It is, however, now generally reported that there is a very high prevalence of thinness among the Indian communities with more than $50.0 \%$ of adolescents being affected ${ }^{11,13}$. The majority of the populations in India are generally poverty stricken and belonging to the poor socioeconomic background, agriculture-based strategies are important for improving household food security and existing nutritional condition in rural adolescents. Moreover, the poor nutritional status among adolescent girls will apparent as an adverse effect on their physical work capacity, health status and poor reproductive outcomes in adulthood ${ }^{6,14,18}$.

It can be summarized that in the present study, the rural adolescents are facing a great risk in terms of double nutritional stress. The prevalence of overweight (BMI $\geq 25 \mathrm{~kg} / \mathrm{m}^{2}$ ) in the present study is $8.13 \%$. The results of National Family Health Survey showed that the prevalence of overweight in children did not increase much in the last decade from $1.60 \%$ (in 1998-1999) to $1.50 \%$ (in 2005-2006) ${ }^{18}$. A significantly lower prevalence of overweight has been reported among rural adolescent from Assam $(0.30 \%)^{13}$ $(p<0.01)$ and rural Wardha $(2.00 \%)^{11}(p<0.01)$ and rural Darjeeling of West Bengal $(0.30 \%)^{10}(p<0.01)$. Recent studies have reported the prevalence of overweight has increased in Indian children and adolescent of Delhi $(22.00 \%)^{20}(p<0.05)$, Punjab $(14.31 \%)^{21}(p<0.05)$, Andhra Pradesh (7.22\%) $(p>0.05)^{22}$ and Pune $(19.9 \%)^{23}$ $(p<0.05)$. Furthermore, the prevalence of overweight and obesity had increased slightly over the past decade in India, but in some urban and higher socioeconomic groups, it reached relatively greater proportions ${ }^{4}$. The appearance of overweight among the adolescents residing in especially urban populations generally attributed due to the changes in the socioeconomic 
status, physical activity and lifestyle $e^{4,21,22}$. Current data suggested that the similar occurrence has also started small segments of the adolescents residing in rural regions in India ${ }^{10,11,13}$. The results of the present study will be useful for the policy makers in their endeavour to formulate various developmental strategies and healthcare programmes of the population concern to reduce the double burden of nutrition in Indian population.

\section{Conclusion}

Moreover, the nutritional status is considered to be an integral component of the overall health of an individual and/or populations. The present study showed that the rural adolescent girls are facing great risks in terms of the double burden of nutrition as thinness which is more pronounced than the overweight. Therefore, the magnitude of thinness is considered to be still a major problem than overweight in rural adolescents in India. The results of the present study would be helpful to reveal the enhanced effectiveness of the ongoing nutritional intervention at targeted population. Since, the ultimate objective of such nutrition assessment studies is to improve human health conditions, therefore there is an urgent need for appropriate nutritional intervention program becomes a priority to reduce malnutrition related health problems especially in adolescents residing in rural areas in India.

Acknowledgement: The author gratefully acknowledges the help and co-operation of the school authorities and local level authorities and participants during the study. The extended help of Department of Anthropology, Assam University, Silchar (Diphu Campus) is also acknowledged.

Funding: Nil

Conflict of Interest: None

Permission from IRB: Yes

\section{References}

1. Nandy S, Irving M, Gordon D, Subramanian SV, Smith GD. Poverty, child undernutrition and morbidity: new evidence from India. Bull World Health Organ 2005;83:210-6

2. Popkin BM. The nutrition transition in the Developing World. Development policy review 2003;21:251-97.

3. Khor GL. Food-based approaches to combat the double burden among the poor: challenges in the Asian context. Asia Pac J Clin Nutr 2008;17:111-5.
4. Wang Y, Chen HJ, Shaikh S, Mathur P. Is obesity becoming a public health problem in India? Examine the shift from under- to overnutrition problems over time. Obes Rev 2009;10:456-74.

5. Kapil U, Sachdev HP. Urgent need to orient public health response to rapid nutrition transition. Indian J Community Med 2012;37:207-10.

6. World Health Organization. 1995. Physical Status: The use and interpretation of Anthropometry. Technical Report Series No. 854. World Health Organization:

7. Cole TJ, Flegal KM, Nicholls D, Jackson AA. Body mass index cut-offs to define thinness in children and adolescents: international survey. BMJ 2007;335(7612):194.

8. Cole TJ, Bellizzi MC, Flegal KM, Dietz WH. Establishing a standard definition for child overweight and obesity worldwide: international survey. BMJ 2000;320:1240-3.

9. Mondal N, Sen J. Thinness is a major underlying problem among Indian children. J Trop Pediatr 2010;56:456-8.

10. Mondal N, Sen J. Assessment of nutritional status among rural adolescents of Darjeeling district, West Bengal, India using anthropometry. Italian J Pub Health 2010;7:54-61.

11. Deshmukh PR, Gupta SS, Bharambe MS, Dongre AR, Maliye C, Kaur S, Garg BS. Nutritional status of adolescents in rural Wardha. Indian J Pediatr 2006;73:139-41.

12. Mondal N, Sen J. Prevalence of undernutrition among children (5-12 years) belonging to three communities residing in a similar habitat in North Bengal, India. Ann Hum Biol 2010;37:198-216.

13. Medhi GK, Hazarika NC, Mahanta J. Nutritional status of adolescents among tea garden workers. Indian J Pediatr 2007;74:343-7.

14. Mondal N. Thinness as major underlying problem among adolescents of Northeast India. J Nepal Paediatr Soc 2014;34:39-47.

15. Singh J, Mondal N. Assessment of nutritional status: A case of tribal children in Assam, Northeast India. J Nepal Paediatr Soc 2013;33:1-7.

16. Rao KM, Laxmaiah A, Venkaiah K, Brahmam GN. Diet and nutritional status of adolescent tribal population in nine states of India. Asia Pac J Clin Nutr 2006;15:64-71.

17. VenkaiahK, DamayantiK, NayakMU, Vijayaraghavan K. Diet and nutritional status of rural adolescents in India. Eur J Clin Nutr 2002;56:1119-25. 
18. Parasuraman S, Kishor S, Singh SK, Vaidehi Y. A Profile of Youth in India. National Family Health Survey (NFHS-3), India, 2005-06. Mumbai: International Institute for Population Sciences; Calverton, Maryland, USA: ICF Macro, 2009.

19. Mondal N, Terangpi M. Prevalence of undernutrition among tribal adolescents of Karbi Anglong district of Assam, Northeast India. Sri Lanka J Child Health 2014; 43: 154-7

20. Sharma A, Sharma K, Mathur KP. Growth pattern and prevalence of obesity in affluent schoolchildren of Delhi. Public Health Nutr 2007;10:485-91.

21. Sidhu S, Kaur N, Kaur R. Overweight and obesity in affluent school children of Punjab. Ann Hum Biol 2006;33:255-9.

22. Laxmaiah A, Nagalla B, Vijayaraghavan K, Nair M. Factors affecting prevalence of overweight among
12- to 17-year-old urban adolescents in Hyderabad, India. Obesity (Silver Spring) 2007;15:1384-90.

23. Khadilkar VV, Khadilkar AV. Prevalence of obesity in affluent school boys in Pune. Indian Pediatr 2004; 41:857-8.

24. Touitou Y, Portaluppi F, Smolensky MH, Rensing L. Ethical principles and standards for the conduct of human and animal biological rhythm research. Chronobiol Int 2004;21:161-70.

25. Weiner JS, Lourie JA. Practical human biology. London: Academic Press, 1981.

26. UlijaszekSJ, Kerr DA. Anthropometric measurement error and the assessment of nutritional status. $\mathrm{Br} \mathrm{J}$ Nutr 1999;82:165-77.

27. Malhotra A, Passi SJ. Diet quality and nutritional status of rural adolescent girl beneficiaries of ICDS in north India. Asia Pac J Clin Nutr 2007;16:S8-16. 